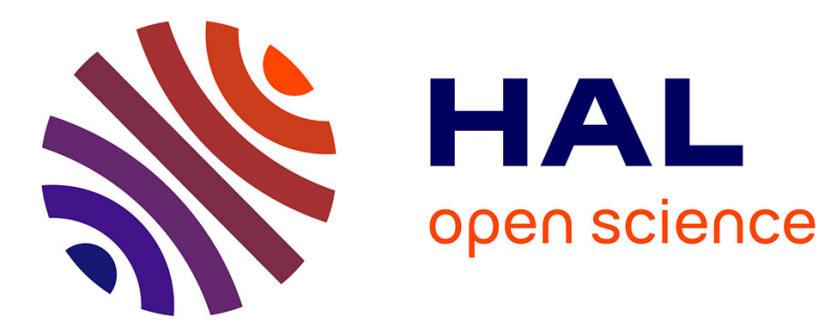

\title{
Integrating multiple scales in rarity assessments of invertebrate taxa
}

Boris Leroy, Alain Canard, Frédéric Ysnel

\section{To cite this version:}

Boris Leroy, Alain Canard, Frédéric Ysnel. Integrating multiple scales in rarity assessments of invertebrate taxa. Diversity and Distributions, 2013, 19 (7), pp.794-803. 10.1111/ddi.12040 . hal-03334362

\section{HAL Id: hal-03334362 \\ https://hal.science/hal-03334362}

Submitted on 3 Sep 2021

HAL is a multi-disciplinary open access archive for the deposit and dissemination of scientific research documents, whether they are published or not. The documents may come from teaching and research institutions in France or abroad, or from public or private research centers.
L'archive ouverte pluridisciplinaire HAL, est destinée au dépôt et à la diffusion de documents scientifiques de niveau recherche, publiés ou non, émanant des établissements d'enseignement et de recherche français ou étrangers, des laboratoires publics ou privés. 


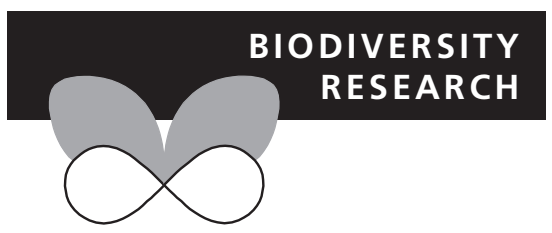

\title{
Integrating multiple scales in rarity assessments of invertebrate taxa
}

\author{
Boris Leroy*, Alain Canard and Frédéric Ysnel
}

Equipe Biodiversité et Gestion des Territoires, UMR 7204 MNHN et Service du Patrimoine Naturel, Université de Rennes I, $263 \mathrm{Av}$. du Gal. Leclerc, 35042, Rennes Cedex, France

${ }^{*}$ Correspondence: Boris Leroy, Equipe Biodiversité et Gestion des Territoires, UMR 7204 MNHN et Service du Patrimoine Naturel, Université de Rennes I, 263 Av. du Gal. Leclerc 35042 Rennes Cedex, France. E-mail: leroy.boris@gmail.com

\begin{abstract}
Aim To provide a procedure for measuring the rarity of both invertebrate species and assemblages of species from multiple scales without the need for fineresolution datasets over broad areas.
\end{abstract}

Location The western Palearctic (WP) and western France.

Methods On the basis of different datasets from different geographical extents, we applied a multiscale rarity weight to species occurrence from multiple scales. Multiscale rarity weights were then averaged at an assemblage level in a multiscale index of relative rarity $\left(I_{\mathrm{RR}}\right)$. These rarity weights were calculated using a flexible, scale-dependent method that ensures equitable contributions of each scale to the final index. We provided a simple two-scale example of the application, on spiders of western France, for which we obtained occurrence information from a regional-extent dataset (regional scale) and a western Palearctic-extent dataset (WP scale). Thus, we showed the necessity of a two-scale approach by successively analysing species occurrence, multiscale rarity weights of species and multiscale indices of species assemblage. Finally, we presented a case study within a nature reserve.

Results Species occurrences are not predictable from one scale to another, and rarity indices of assemblages are poorly congruent among scales, which supports the necessity of a two-scale approach. Multiscale rarity weights accurately showed information on species rarity from both scales. Multiscale indices of assemblages were congruent but with additional information over each onescale index.

Main conclusions The novelty of the multiscale method developed here is to accurately combine different datasets of varying extents and resolutions to provide multiscale rarity weights for species and indices for assemblages. Given the increasing availability of datasets for invertebrate taxa, this method represents a significant improvement for rarity and conservation studies on invertebrates.

\section{Keywords}

Management monitoring, occurrence data, rare species, rarity hotspots, spiders, western Palearctic.

\section{INTRODUCTION}

Ecology is scale dependent; hence, the scale with which we assess ecological systems affects our perspective of the system (Schneider, 2001). This is valid for rarity studies: a species may be considered rare on a local scale, yet common at a regional or global scale (Flather \& Sieg, 2007). Indeed, processes controlling the distribution of species have relative importance that change with scale (McGill, 2010). Thus, rarity is also scale dependent, and growing awareness of this consideration has led ecologists to quantify rarity across multiple scales (Rabinowitz, 1981; Hartley \& Kunin, 2003; Fagan et al., 2005; He \& Condit, 2007).

Rabinowitz (1981) developed a typology of rarity based on three axes of species distribution, each relating to a different scale of analysis: geographical range size, habitat specificity and local density. This typology has been widely applied in conservation studies (e.g. Kattan, 1992; Abellán et al., 2005; Broennimann et al., 2005; Isaac et al., 2009); however, apart from few rare examples (Fattorini, 2010; Fattorini et al., 2012), its application on lesser-known taxa, such as invertebrates, is often problematic because of lack of data on the 
abundance and habitat specificity or difficulties in obtaining such data. In contrast, data on geographical range size (e.g. occurrence data) are more readily available, and thus, most multiscale approaches are specifically developed for this. The most frequent multiscale methods based on range size are the scale-area or occupancy-area curves (Fagan et al., 2002; Hartley \& Kunin, 2003; Fagan et al., 2005; He \& Condit, 2007; Azaele et al., 2012). Scale-area curves consist of plotting the area occupied by a species as a function of scale (defined as a grid-cell area); these curves were used for measuring the extinction risk (Fagan et al., 2002; Hartley \& Kunin, 2003; Fagan et al., 2005). A shared conclusion of multiscale studies is the necessity of using and combining information from multiple scales when investigating species rarity (e.g. Warman et al., 2004), especially when making a link between rarity and extinction risk (Hartley \& Kunin, 2003; Fagan et al., 2005). Thus, for a given study, different conservation priorities might have been chosen had a different arbitrary scale been chosen as a standard (Pearman, 1996 in Hartley \& Kunin, 2003). However, although published conservation studies based on multiscale analyses can be found for vertebrates (e.g. Fagan et al., 2002, 2005) and plants (Pärtel et al., 2005), the task is much more difficult for invertebrates. An interesting two-scale (regional and European) method for assessing butterflies was proposed by Fattorini (2009). However, this method uses the Red List statuses of species, which are lacking for most invertebrates (Rands et al., 2010; Zamin et al., 2010; but see Cardoso et al., 2011a). In fact, the majority of rarity studies on invertebrates are single-scale studies, irrespective of their aim of biodiversity conservation (e.g. Samu et al., 2008; Dapporto \& Dennis, 2008) or others (e.g. McCreadie \& Adler, 2008). Therefore, integration of multiple scales when investigating invertebrate rarity for conservation studies is required to improve reliability and reduce biases.

Although scale-area curves are a promising multiscale approach for invertebrates, we identified two major issues precluding their application in invertebrate conservation studies. First, the lack of broad-scale distributional data for most invertebrate taxa (Cardoso et al., 2011b) is restrictive. Indeed, to be meaningful, scale-area curves require several different scales, that is, they require a broad area dataset at a fine resolution. However, distribution data for invertebrates are either at fine resolutions but on restricted scales (e.g. a region or a small country) or at broad scales but with coarse resolutions (e.g. Fauna Europaea, 2011). Hence, for invertebrates, scale-area curves will most often be applied using a restricted number of scales. Second, the diversity of most invertebrate taxa implies conservation at the assemblage level, whereas multiscale methods were designed at the species level. Consequently, most conservation studies on invertebrate taxa focus on either surrogate species for assemblages or habitats (Cardoso et al., 2011b), or assemblage-level assessments such as scoring procedures (e.g. Dapporto \& Dennis, 2008; Simaika \& Samways, 2009; Fattorini, 2010; Leroy et al., 2012). Therefore, a multiscale rarity metric at the assemblage level would be a valuable improvement to invertebrate conservation studies. The aim of this study is to provide a procedure to measure the rarity of both invertebrate species and assemblages from multiple scales, without the need for fine-resolution datasets over broad areas.

To generalize this procedure, it has to be based on the most available data regardless of the taxa: occurrence data. The basic assumption is that because we lack a broad-extent fine-scale database, we can combine multiple datasets to obtain a multiscale procedure. Indeed, this is possible because of the increasing availability of datasets (see Jetz et al., 2012), irrespective of whether local, regional, or national scales (e.g. atlas data or regional surveys such as Harvey et al., 2002), or even larger scales (e.g. datasets combining occurrence data from different sources such as Global Biodiversity Information Facility (GBIF, 2012) or species lists from different countries such as Fauna Europaea, 2011). Thus, scale is here defined as the extent of the considered dataset. We apply the method introduced by Leroy et al. (2012) to calculate a multiscale rarity weight for species from species occurrences at different scales. Multiscale rarity weights are then integrated at the assemblage level with the Index of Relative Rarity; the advantages were discussed in Leroy et al. (2012).

We describe the multiscale weighting method and index of relative rarity $\left(I_{\mathrm{RR}}\right)$ and provide a two-scale example of analysis on spiders of western France. At a regional scale, spider occurrences are obtained from a fine-resolution database for western France (Pétillon et al., 2007a). At a biogeographical scale, spider occurrences are obtained from a coarse resolution database for western Palearctic (WP) (Canard, 2005, updated in 2011). We first analyse the relationship between regional and WP occurrence of the species and then apply the multiscale index on a case study in a national nature reserve. On the basis of these examples, we discuss the improvements provided by a multiscale rarity measure over single-scale rarity measures.

\section{METHODS}

\section{Multiscale weights of rarity}

Rarity weights are calculated on the basis of species occurrence at each scale with a weighting method that can be adjusted according to a user-chosen rarity cut-off point (Leroy et al., 2012). Rare species receive rarity weights that increase exponentially when their occurrence falls below a rarity cut-off point. Thus, weights of rare species (with occurrence lower than the cut-off) are amplified, whereas weights of common species (with occurrence higher than the rarity cut-off) tend to be zero. This method has been proven to be less biased than the other existing methods, mainly because of its flexibility (Leroy et al., 2012). Here, we applied an improved and easier version of weighting function from Leroy et al. (2012) (see Appendix S1 in Supporting Information). Adjusting the function to the selected rarity cut-off 
point formerly required a numerical approximation that made it difficult to implement; therefore, we fitted a weighting function with the same properties as in Leroy et al. (2012), but where the rarity cut-off point is a direct parameter of the function (Eqn. 1). The function is adjusted such that, at the rarity cut-off point, species weight is always equal to $5 \%$ of the maximum weight. Below the rarity cut-off, weights increase exponentially; above the rarity cut-off, weights tend to be zero.

First, each species received as many rarity weights $\left(w_{i j}\right)$ as there were scales according to the following formula:

$$
w_{i j}=\exp \left(-\left(\frac{Q_{i j}-Q_{j \min }}{r_{j} \times Q_{j \max }-Q_{j \min }} \times 0.97+1.05\right)^{2}\right)
$$

where all parameters are defined at the considered scale $j$ : $Q_{i j}$, occurrence of species $i ; Q_{j \text { min }}$ and $Q_{j \max }$, minimum and maximum occurrences, respectively; and $r_{j}$, chosen rarity cut-off point (as a percentage of maximum occurrence). The maximum occurrence is defined as the highest occurrence found among species at scale $j$.

Second, the multiscale weight $\left(w_{M i}\right)$ of each species was calculated by taking the sum of each one-scale rarity weight:

$$
w_{M i}=\sum w_{i j}
$$

\section{Scale dependency of rarity cut-off points}

The rarity cut-off point is typically defined in relation to the frequency distribution of species occurrence (Gaston, 1994; Flather \& Sieg, 2007). As these distributions often differ among scales, rarity cut-off points are likely to be different among scales (Fig. 1a,b). If an arbitrary cut-off is chosen, a scale might be promoted because more species will be classified as rare (Fig. 1c) for this particular scale; consequently, the results of the community index might be biased towards this particular scale. Conversely, if a scale-dependent cut-off is chosen (according to Gaston's quartile definition) (Fig. 1d), equal proportions of species will be classified as rare at all scales. Hence, contributions of each scale to the community index should be roughly equal. Here, we provide evidence for this 'equitability' property of multiscale $I_{\mathrm{RR}}$ on simulated datasets (see Appendix S2).

\section{Spider occurrence data}

We provide a two-scale example of the described method on spiders of western France. At a regional scale, spider occurrences, defined as the number of grid cells $(16 \times 16$ cells grid, approximately $683 \mathrm{~km}^{2}$ per cell) in which the species were found, were obtained from the western France spider database (Pétillon et al., 2007a). At a biogeographical scale, spider occurrences were obtained from the Catalogue of Spider Species from Europe and the Mediterranean Basin (Canard, 2005; taxonomy and occurrence of species updated in 2011). This coarse-resolution database references the occurrences of 5692 spider species totalling to 33,932 records across 75 units. Spatial referencing of records was based on biogeopolitical units, and therefore, of unequal size. Because island faunas often differ from country fauna, islands or groups of islands were considered as separate units (Ysnel et al., 2008; see Appendix S3). Therefore, the WP occurrence of a species was defined as the number of units in which the species was found. Here, only the 705 spider species occurring in western France were considered. Thus, each species had both regional and WP occurrence.

\section{Relevance of a two-scale approach}

Because a two-scale analysis is relevant only if no strong linear relationship is observed between the scales, we analysed the relationship between regional and WP occurrences of the species and fitted linear and polynomial regression models to determine the type and strength of the relationship between regional and WP occurrence of spider species.

\section{Choice of rarity cut-off points}

As emphasized previously, the selection of rarity cut-off points should ensure scale-dependent cut-offs. We recommend defining cut-offs on the basis of either Gaston's quartile definition (rare species are the $25 \%$ species with lowest occurrence) or guidelines by Leroy et al. (2012) (rarity cut-off point is the occurrence at which the average proportion of rare species in local assemblages is 25\%). The latter ensures that the chosen cut-off will be sufficient to distinguish among assemblages of species (see Discussion in Leroy et al., 2012) but is calculated from a set of comparable assemblages. As our regional database had 166 assemblages of spiders on the basis of standardized samplings, we used the guidelines by Leroy et al. to calculate the cut-offs.

\section{Two-scale weights of rarity of western France spider species}

On the basis of the calculated cut-offs at each scale, we calculated two-scale weights of the 705 spider species occurring in western France. We analysed the distribution parameters of the two-scale weights (minimum, maximum, median and mean $[ \pm$ standard deviation (SD) $]$ ) according to four rarity categories that can be expected from a two-scale approach: (1) species rare at both regional and WP scales, (2) species rare for only regional scale, (3) species rare for only WP scale and (4) species not rare.

\section{Index of relative rarity}

The $I_{\mathrm{RR}}$ of an assemblage is calculated as the average weight of rarity of all the species of the assemblage. The $I_{\mathrm{RR}}$ is subsequently normalized between 0 and 1: $I_{\mathrm{RR}}=\left(\left[\Sigma\left(w_{i}\right) / S\right]-\right.$ $\left.w_{\min }\right) /\left(w_{\max }-w_{\min }\right)$ where $w_{i}$ is the weight of the $i$ th species 


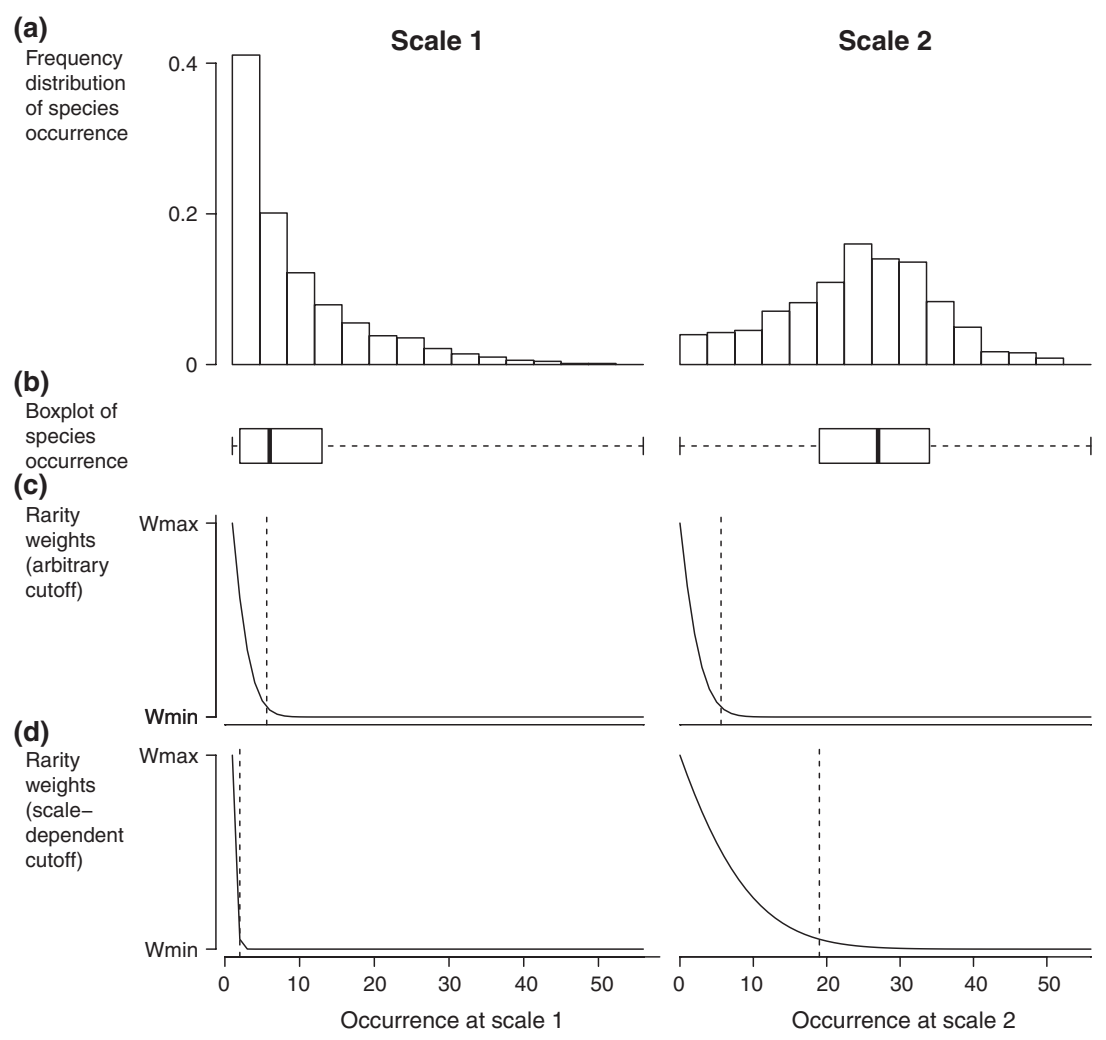

Figure 1 Theoretical illustration of the scale dependency of rarity cut-off points on the basis of our spider species datasets. (a) Histogram of frequency distributions of species occurrences for both scales. (b) Box plots of frequency distributions of species occurrences for both scales. (c) Rarity weighting function $\left(w_{i j}\right)$ with an arbitrary cut-off $(10 \%$ of the maximum, dashed lines). (d) Rarity weighting function with a scaledependent cut-off based on Gaston's quartile definition; dashed lines: rarity cut-offs of each scale. of the assemblage; $S$, species richness; and $w_{\min }$ and $w_{\max }$, minimum and maximum possible weights, respectively.

\section{Congruencies between one-scale and two-scale indices}

For each of the 166 assemblages of spiders in our regional database, we calculated three indices: (1) a regional-scale $I_{\mathrm{RR}}$ based only on regional rarity weights, (2) a WP $I_{\mathrm{RR}}$ based only on WP weights and (3) a multiscale $I_{\mathrm{RR}}$ based on multiscale rarity weights.

To assess the relevance of the multiscale index, we analysed the congruence between regional and WP scale $I_{\mathrm{RR}}$. We assumed that if both regional and WP $I_{\mathrm{RR}}$ were strongly congruent, then there is no need for a two-scale index because one scale would be sufficient to capture the information provided by both scales. Then, we analysed the congruence between the two-scale $I_{\mathrm{RR}}$ and each one-scale $I_{\mathrm{RR}}$ (regional and WP). Our second assumption was that if the two-scale index did not show any congruence with one-scale indices, then it has failed to capture information from these scales. Congruencies were assessed using Spearman rank correlation coefficient.

\section{Case study in a nature reserve}

To provide an example, we applied the two-scale $I_{\mathrm{RR}}$ on a case study of 15 sampled assemblages of 225 spider species of the National Nature Reserve of Séné (France, $47.61^{\circ} \mathrm{N}$, $2.71^{\circ} \mathrm{W}$ ), which we extracted from the database. We chose these case study assemblages because they were sampled from contrasting habitats: wet grasslands, salt marshes, salt meadows, several disturbed and undisturbed meadows, open lawn, heathlands and hedgerows. Salt marshes and sub-halophytic meadows are known to host stenotopic, halophilous species (Pétillon et al., 2008), which is not the case with the other sampled habitats. Because salt marshes are common in western France but extremely restricted at the WP scale (Pétillon et al., 2007b), we expected their rarity value to be influenced by the presence of species rare at the WP scale. Ten of the presented assemblages had already been compared with the $I_{\mathrm{RR}}$ single-scale version (Leroy et al., 2012). We calculated and analysed the single- and two-scale $I_{\mathrm{RR}}$ values and ranks of all 15 spider assemblages.

\section{Data analyses}

All data analyses were performed using $\mathrm{R}$ ( $\mathrm{R}$ Development Core, 2012). Single and multiscale rarity weights and $I_{\mathrm{RR}}$ were calculated using the new package 'Rarity' published on the Comprehensive R Archive Network along with this article.

\section{RESULTS}

\section{Relationship between regional and WP occurrence of spiders}

The relationship between regional and WP occurrences of spider species is best described by a second-degree polynomial model $\left(R^{2}=0.401, \quad P<0.0001, n=705\right)$ (Fig. 2$)$. Nearly all spiders having low WP occurrence also had low 


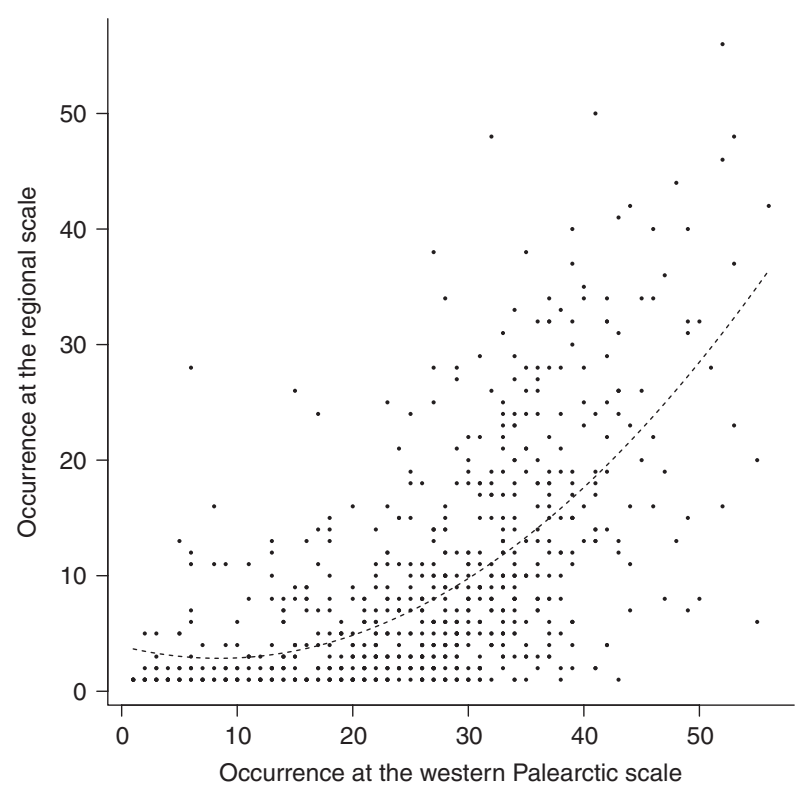

Figure 2 Occurrence of spider species at the regional scale as a function of their occurrence at the western Palearctic (WP) scale. The regional-scale occurrence is the number of cells in which species have been found from a regional-extent dataset $(16 \times 16$ cells grid, ca. $683 \mathrm{~km}^{2}$ per cell). The WP scale occurrence is the number of biogeopolitical units in which species have been found from a WP extent dataset (see Appendix S3). Dashed line: second-degree polynomial model $\left(R^{2}=0.401, P<0.0001\right.$, $n=705$ ) best describing the relationship between regional and WP occurrence of spider species.

regional occurrence. In contrast, spiders having low regional occurrence could have had low, moderate or high WP occurrence. Spider species with the highest WP occurrences also had the highest regional occurrences.

\section{Two-scale rarity weights of western France spiders}

The regional rarity cut-off was $23.2 \%$ of the maximum occurrence (i.e. for species occurring in less than 13 grid cells). The WP rarity cut-off was $50.5 \%$ of the maximum occurrence (i.e. for species occurring in $<29$ areas). We compared species weights (see Appendix S4) according to the four categories of rarity that we can expect from a two-scale approach (Table 1):

1. 350 species $(49.7 \%)$ were defined as rare at both scales. Their weights were, on average, higher than those of the other categories.
2. 165 species $(23.4 \%)$ were classified as rare at the regional scale but not at the WP scale. Their weights were, on average, half the weights of species rare at both scales.

3. 37 species $(5.2 \%)$ were classified as rare at the WP scale but not at the regional scale. Their weights were, on average, half the weights of species regionally rare.

4. 153 species $(21.7 \%)$ were not classified as rare. Their weights were, on average, very low $(0.02 \pm 0.02)$. Intriguingly, some species could have had weights higher than those of the regionally or WP-rare species $(0.09$ vs. 0.07 or 0.05 , respectively). The occurrence of these species was extremely close to the rarity cut-off point at both scales. For example, Dendryphantes rudis, whose regional and WP occurrences were 13 and 29, respectively, had a two-scale weight of 0.09 .

\section{Two-scale indices of relative rarity vs. one-scale $I_{\mathrm{RR}}$ of western France spider assemblages}

There was a significant but mediocre congruence between regional and WP indices of the 166 spider assemblages in our database (Spearman's $\rho=0.37, P<0.0001, n=166$ ). In contrast, the two-scale indices of the 166 assemblages were strongly correlated with those of the regional (Spearman's $\rho=0.87, P<0.0001, n=166$ ) and WP indices (Spearman's $\rho=0.74, \quad P<0.0001, n=166)$. Nevertheless, there were marked differences between one-scale and two-scale $I_{\mathrm{RR}}$, and the majority of sites received a high (i.e. worse) rank with the two-scale $I_{\mathrm{RR}}$ (see Appendix S5). The number of sites receiving a higher or lower rank was similar regardless of the scale. Very few sites received identical ranks between onescale and two-scale $I_{R R}$.

\section{Case study in a nature reserve}

Indices of the assemblages of the nature reserve differed and, on average, regional $I_{\mathrm{RR}}$ were higher and more dispersed than WP $I_{\mathrm{RR}}$ (Table 2). Two-scale $I_{\mathrm{RR}}$ corresponded to the arithmetic mean between regional and WP $I_{\mathrm{RR}}$. This is a mathematical consequence of the formulas, because one-scale weights are summed into two-scale weights and then averaged in the assemblage index. The following different patterns were distinguished: (1) six assemblages had similar rankings among indices because of either low (wet grassland S2, open lawn S8), intermediate (grazed salt marsh S5, postcultural meadow S9) or high $I_{\mathrm{RR}}$ (Atlantic salt scrub S7,

Table 1 Different categories of species rarity that can be expected from a two-scale approach. For each category: number of western France spider species falling in that category and two-scale weights of rarity (minimum, maximum, median and mean ( \pm standard deviation $[S D]))$.

\begin{tabular}{|c|c|c|c|c|c|c|}
\hline Regional scale & West-Palearctic scale & Number of species & Minimum weight & Maximum weight & Median weight & Mean weight (SD) \\
\hline Rare & Rare & 350 & 0.11 & 2.00 & 0.90 & $0.93(0.47)$ \\
\hline Rare & Not rare & 165 & 0.07 & 1.05 & 0.36 & $0.43(0.30)$ \\
\hline Not rare & Rare & 37 & 0.05 & 0.76 & 0.11 & $0.19(0.17)$ \\
\hline Not rare & Not rare & 153 & $<0.01$ & 0.09 & 0.02 & $0.02(0.02)$ \\
\hline
\end{tabular}


Table 2 Regional scale, western Palearctic scale and two-scale Indices of Relative Rarity $\left(I_{\mathrm{RR}}\right)$ of spider assemblages from the Séné National Nature Reserve of and corresponding rankings.

\begin{tabular}{|c|c|c|c|c|c|c|c|c|c|}
\hline \multirow[b]{2}{*}{ Label } & \multirow[b]{2}{*}{ Habitat } & \multirow[b]{2}{*}{$\begin{array}{l}\text { Management } \\
\text { mode }\end{array}$} & \multicolumn{3}{|l|}{$I_{\mathrm{RR}}$} & \multicolumn{3}{|l|}{ Ranking } & \multirow[b]{2}{*}{$\begin{array}{l}\text { Species } \\
\text { richness }\end{array}$} \\
\hline & & & Regional & $\begin{array}{l}\text { Western } \\
\text { Palearctic }\end{array}$ & Two-scale & Regional & $\begin{array}{l}\text { Western } \\
\text { Palearctic }\end{array}$ & Two-scale & \\
\hline S1 & Wet grassland & Grazed & 0.041 & 0.075 & 0.058 & 14 & 7 & 13 & 43 \\
\hline S2 & Wet grassland & - & 0.061 & 0.055 & 0.058 & 12 & 12 & 13 & 41 \\
\hline S3 & Atlantic salt meadow & Grazed & 0.081 & 0.069 & 0.075 & 9 & 10 & 8 & 56 \\
\hline S4 & Atlantic salt meadow & - & 0.090 & 0.067 & 0.078 & 8 & 11 & 6 & 34 \\
\hline S5 & Atlantic salt marsh & Grazed & 0.077 & 0.070 & 0.074 & 10 & 9 & 9 & 55 \\
\hline S6 & Atlantic salt marsh & - & 0.092 & 0.136 & 0.114 & 5 & 1 & 1 & 19 \\
\hline S7 & Atlantic salt scrub & - & 0.121 & 0.093 & 0.107 & 2 & 2 & 2 & 49 \\
\hline S8 & Open lawn & Mowed & 0.033 & 0.033 & 0.033 & 15 & 15 & 15 & 34 \\
\hline S9 & Post-cultural meadow & Mowed & 0.104 & 0.081 & 0.093 & 4 & 6 & 4 & 40 \\
\hline $\mathrm{S} 10$ & Tallgrass meadow & - & 0.059 & 0.086 & 0.072 & 13 & 4 & 11 & 43 \\
\hline S11 & Fallow land & - & 0.092 & 0.072 & 0.082 & 5 & 8 & 5 & 72 \\
\hline S12 & Gorse thickets & - & 0.092 & 0.035 & 0.064 & 5 & 14 & 12 & 40 \\
\hline S13 & Heathlands & - & 0.123 & 0.087 & 0.105 & 1 & 3 & 3 & 46 \\
\hline S14 & Monospecific hedgerows & - & 0.063 & 0.082 & 0.073 & 11 & 5 & 10 & 37 \\
\hline S15 & Deciduous hedgerows & - & 0.105 & 0.051 & 0.078 & 3 & 13 & 6 & 54 \\
\hline
\end{tabular}

heathlands S13); (2) two assemblages had marked differences between regional and WP $I_{\mathrm{RR}}$ and ranks, which resulted in intermediate two-scale $I_{\mathrm{RR}}$ and rankings (tallgrass meadow S10, deciduous hedgerows S15); (3) five assemblages had marked differences between regional and WP $I_{R R}$ and ranks, but the resulting two-scale ranks were very close to either the regional (grazed wet grasslands S1, fallow land S11, monospecific hedgerows S14) or WP (ungrazed salt marsh S6, gorse thickets S12) ranks; (4) surprisingly, two assemblages had better two-scale ranks than both their one-scale ranks (grazed and ungrazed salt meadows S3 and S4, respectively).

Among these different patterns, the most striking results were the top three assemblages according to the two-scale $I_{\mathrm{RR}}$. Most importantly, the ungrazed salt marsh $\mathrm{S} 6$ was ranked first, although only fifth with the regional $I_{\mathrm{RR}}$. This assemblage had a very high WP $I_{\mathrm{RR}}$. Salt scrub (S7) $I_{\mathrm{RR}}$ were clearly congruent between scales and thus were ranked second, and heathlands (S13) were ranked third.

\section{DISCUSSION}

In this study, we addressed the lack of inclusion of multiple scales in conservation studies of invertebrate taxa using an innovative approach based on datasets of different extents. We provided an example carried out on spiders for which we calculated species occurrence using two different datasets, corresponding to two different scales: a regional-scale dataset (western France) and a biogeographical scale dataset (western Palearctic). We demonstrated that a multiscale approach is necessary because of the lack of predictability of species occurrence between scales, and the poor congruence of rarity indices of assemblages among scales. Therefore, we integrated species occurrence from both scales into multiscale rarity weights for species and multiscale rarity indices for assemblages of species, using a new multiscale method. The major improvement of the multiscale method developed here is that it overcomes the gap between datasets of different extents, regardless of the resolution. In other words, the difference between our multiscale method and the classical scale -area curves is that the former is based on different datasets of varying extents, whereas the latter is designed for a single, high-resolution dataset with a fixed extent. Ideally, a dataset with a biogeographical extent (large enough to encompass complete species ranges) and fine resolution would allow the application of scale-area curves. In practice, such datasets do not exist for invertebrate taxa, and when broad-extent datasets are available, they often comprise coarse resolutions such as geopolitical units of unequal sizes (e.g. Fauna Europaea, 2011). Hence, our multiscale method is a valuable improvement to conservation studies, allowing any rarity assessment to integrate information on species rarity at different spatial scales. In a regional-scale assessment of rarity of species and assemblages, we demonstrated how we could integrate information on rarity at a larger scale such as the western Palearctic.

The most important part of the design of such a multiscale method is the calculation of species rarity weights; the final $I_{\mathrm{RR}}$ of assemblages of species corresponds to the average rarity weight of species of the assemblage. The formula transforming species occurrence into rarity weights is a critical feature. In most single-scale studies (e.g. Ysnel et al., 2008; Kier et al., 2009), rarity weights are calculated as the inverse of occurrence; however, although intuitive, this method was criticized in Leroy et al., (2012) for its lack of flexibility, which could bias the results when comparing different assemblages. Leroy et al. (2012) proposed a flexible method to assess species rarity weights that ensure appropriate 
calculation according to the considered taxa, spatial scales and geographical areas. As shown in this study, such a flexible weighting method was necessary to avoid bias in the final index towards one of the considered scales. Our basic assumption was that there should initially be neutrality among scales and that neutrality should not be transgressed because of the mathematical characteristics of the method. Nevertheless, if the user chooses to promote a given scale, either a high cut-off can be assigned to that scale such that more number of species receive high weights or a low cut-off can be assigned to the other scales. The cut-off definition applied here was based on the guidelines by Leroy et al. (2012). This cut-off definition is more relaxed than that by Gaston because it is applied to assemblages of species rather than to the entire database. This explains the high numbers of species classified as rare at each scale; however, species did not necessarily receive high weights because they were classified as rare, which should mitigate any bias associated with a relaxed definition of rarity, as warned by Grenyer et al. (2006).

Given that previous multiscale studies have clearly shown that rarity patterns vary with scales (Hartley \& Kunin, 2003), the possibility of integrating multiple scales in rarity studies for invertebrates is a major improvement. Because different scales mean different extinction processes (Hartley \& Kunin, 2003), the use of a single scale means that extinction processes acting at other scales are overlooked, which implies partially informed conservation studies. This risk was illustrated by our finding that the regional occurrence of spider species was not linearly correlated to their WP occurrence. Hence, species that were rare at the regional scale could be either rare or common at the WP scale. Therefore, species rare at both scales would have been overlooked in a singlescale study, even though they are the most at-risk species. Conversely, the two-scale rarity weights assigned to species were consistent according to the different categories of rarity resulting from a two-scale approach. Species rare at both scales received, on average, a higher weight than species rare at a single scale, and weights were mitigated according to species occurrence; therefore, the multiscale weighting method proposed here accurately represents species rarity according to the considered scales.

A further illustration of the limitations of a single-scale study is the very weak congruence among single-scale indices of species assemblages. This implies that the arbitrary choice of one scale or the other would have led to very different rankings. Conversely, this also implies that these two scales provide different, and therefore, complementary information on the rarity of species assemblages. Additionally, the two-scale $I_{\mathrm{RR}}$ was strongly congruent with both one-scale indices. The twoscale $I_{\mathrm{RR}}$, therefore, combines these two complementary scales to provide additional and consistent information over each one-scale index. The final rankings based on the two-scale $I_{\mathrm{RR}}$ are subsequently different from, but related to, each singlescale ranking. A good illustration of the differences between one-scale and multiscale indices is the case study at the Séné
Nature Reserve. Rankings appeared to be scarcely identical among indices, which seemed logical given the low congruence between one-scale indices. Nevertheless, some assemblages showed similar patterns among indices, such as the last-ranked spider assemblage of the very disturbed open lawn S8, comprising only ubiquitous species. Another interesting example is the assemblage of the Atlantic salt scrub, comprising high proportions of species rare at both scales, resulting in a constant second rank among indices. Another interesting pattern was that the two-scale rankings were often similar to one of the one-scale rankings. For example, the ungrazed Atlantic salt marsh S6 was ranked first with the WP $I_{\mathrm{RR}}$, fifth with the regional $I_{\mathrm{RR}}$, but first with the two-scale $I_{\mathrm{RR}}$. This final first ranking was obtained because of a very high two-scale $I_{\mathrm{RR}}$ that, in turn, was explained by a very high WP value. In other words, the Atlantic salt marsh contained a very high proportion of species very rare at the WP scale, but relatively frequent at the regional scale. Indeed, salt marshes are relatively common in western France but extremely restricted at the WP scale (Pétillon et al., 2007b; Leroy et al., 2012). In contrast, some assemblages had nearly opposite rankings between one-scale indices, such as the deciduous hedgerows S15 characterized by the presence of regionally rare species that were relatively widespread at the WP scale. Unexpectedly, two-scale ranks of assemblages were sometimes worse (S2) or better (S3 and S4) than both one-scale ranks. The former case can occur when the majority of species rare at one scale are very frequent at the other. The latter case can occur when assemblages contain species that are rare at both scales, or at least that are rarer at both scales than the average of the compared assemblages.

The methodological improvements proposed here might represent a significant step in rarity metrics for both species and assemblages; however, some important caveats need to be considered. First, the reliability of the results clearly depends on the chosen occurrence datasets (see Discussion in Leroy et al., 2012). Occurrence datasets often suffer numerous biases, mainly because they were not initially designed for such analyses (see Discussion in Pearman et al., 2006). When applicable, completeness metric should be applied to quantify the quality of the dataset (Soberón et al., 2007) and moderate interpretations. One might also question the reliability of coarse-resolution datasets such as the WP dataset used here. Similar coarse-scale data have previously been utilized in the assessment of species vulnerability for conservation prioritization (Abellán et al., 2005). To be as accurate as possible from a biogeographical point of view, geopolitical units of the WP were subdivided into biogeopolitical units. Accordingly, islands and island groups were separated from mainland areas and split according to the composition of their fauna (Canard, 2005). Areas north of the biogeographical limit of the Sahara Desert were included because their spider fauna is shared with that of areas north of the Mediterranean Sea (e.g. Canard, 1989). Although such a spatial referencing of records allows accurate representation of data within a reasonable amount of time, it implies that the units are of unequal sizes. Such 
differences in surfaces among areas introduce a bias in occurrence estimation because species with a large range in a single large area will appear rarer than species with a small range overlapping different areas. Nevertheless, we believe that even with such coarse resolution, a combination of the complementary WP scale with the regional scale provides a benefit by emphasizing the rarest or least known species. Furthermore, from a conservation point of view, the possibility of discriminating species that are regionally rare but common elsewhere from species that are rare at both scales justifies the usefulness of the coarse-scale dataset. Another drawback of coarse-scale datasets is the occurrence of nonnative accidental species for a few times in a single region, and therefore, mistakenly receiving a very high rarity weight. Only rigorous checking of species lists, synonymy, and when available, specimens, can avoid such errors. Such rigorous checking was applied to the WP dataset in this study, and non-native species were excluded from rarity analyses.

Another caveat is that when assemblages are ranked, the ranking is relative (i.e. assemblages are ranked in comparison with each other). To have an idea of the rarity value according to the considered region, the regional ranking method proposed by Leroy et al. (2012) can be applied with the multiscale $I_{\mathrm{RR}}$. For example, a particular sampled habitat can be compared with all the assemblage sampled in the same habitat of the reference region. Once the limits of such a method are considered, we believe that because it is flexible and robust, it should clearly improve rarity evaluations for various studies (e.g. monitoring management practices, changes in land use, identification of rarity hotspots in a given region). Moreover, because this method is easy to implement, we hope that it will be used to improve the placement of numerous neglected invertebrate taxa in applied conservation. Regarding spiders, the availability of regional or national lists for many European countries (e.g. U.K.: Harvey et al., 2002; CZ: Buchar et al., 2002) and two European-scale databases (Canard, 2005; Fauna Europaea, 2011) should make it easy to implement throughout the continent. As a final consideration, the principle behind our approach, that is, combining different datasets of different extents, can be applied to improve regional applications of the IUCN criteria (i.e. IUCN, 2003) for taxa without evaluations at larger spatial scales.

\section{ACKNOWLEDGEMENTS}

We are grateful to Céline Bellard (UMR ESE, Univ. Paris Sud) and Simon Potier (Univ. Rennes 1) for constructive criticisms on the earlier versions of this manuscript.

\section{REFERENCES}

Abellán, P., Sánchez-Fernández, D., Velasco, J. \& Millán, A. (2005) Assessing conservation priorities for insects: status of water beetles in southeast Spain. Biological Conservation, 121, 79-90.
Azaele, S., Cornell, S.J. \& Kunin, W.E. (2012) Downscaling species occupancy from coarse spatial scales. Ecological Applications, 22, 1004-1014.

Broennimann, O., Vittoz, P., Moser, D. \& Guisan, A. (2005) Rarity types among plant species with high conservation priority in Switzerland. Botanica Helvetica, 115, 95-108.

Buchar, J., Rưžička, V. \& Merrett, P. (2002) Catalogue of spiders of the Czech Republic. Peres, Prague.

Canard, A. (1989) Contribution à l'étude des aranéides du Parc Naturel Régional de la Corse. I: Données générales sur les peuplements d'aranéides de Corse: catalogue provisoire des espèces, premières données sur la composition des peuplements. Travaux scientifiques-Parc naturel régional et réserves naturelles de Corse, 20, 1-52.

Canard, A. (2005) Catalogue of spider species from Europe and the Mediterranean basin. Revue Arachnologique, 15, 1-408.

Cardoso, P., Borges, P.A.V., Triantis, K.A., Ferrández, M.A. \& Martín, J.L. (2011a) Adapting the IUCN red list criteria for invertebrates. Biological Conservation, 144, 2432-2440.

Cardoso, P., Erwin, T.L., Borges, P.A.V. \& New, T.R. (2011b) The seven impediments in invertebrate conservation and how to overcome them. Biological Conservation, 144, 2647-2655.

Dapporto, L. \& Dennis, R.L.H. (2008) Island size is not the only consideration. Ranking priorities for the conservation of butterflies on Italian offshore islands. Journal of Insect Conservation, 12, 237-249.

Fagan, W.F., Unmack, P.J., Burgess, C. \& Minckley, W. (2002) Rarity, fragmentation, and extinction risk in desert fishes. Ecology, 83, 3250-3256.

Fagan, W.F., Aumann, C., Kennedy, C.M. \& Unmack, P.J. (2005) Rarity, fragmentation, and the scale dependence of extinction risk in desert fishes. Ecology, 86, 34-41.

Fattorini, S. (2009) Assessing priority areas by imperilled species: insights from the European butterflies. Animal Conservation, 12, 313-320.

Fattorini, S. (2010) Biotope prioritisation in the Central Apennines (Italy): species rarity and cross-taxon congruence. Biodiversity and Conservation, 19, 3413-3429.

Fattorini, S., Cardoso, P., Rigal, F. \& Borges, P.A.V. (2012) Use of arthropod rarity for area prioritisation: insights from the Azorean Islands. PLoS ONE, 7, e33995.

Fauna Europaea (2011) Fauna Europaea version 2.4. Available at: http: www.faunaeur.org (accessed 25 June 2012).

Flather, C.H. \& Sieg, C.H. (2007) Species rarity: definition, causes and classification. Conservation of rare or little known species (ed. by M.G. Raphael and R. Molina), pp. 40 -66. Island Press, Washington, DC.

Gaston, K.J. (1994) Rarity. Chapman \& Hall, London.

GBIF (2012) Global biodiversity information facility. GBIF, Copenhagen. Available at: http: www.gbif.org (accessed 25 June 2012).

Grenyer, R., Orme, C.D.L., Jackson, S.F., Thomas, G.H., Davies, R.G., Davies, T.J., Jones, K.E., Olson, V.A., Ridgely, R.S. \& Rasmussen, P.C. (2006) Global distribution and conservation of rare and threatened vertebrates. Nature, 444, 93-96. 
Hartley, S. \& Kunin, W.E. (2003) Scale dependency of rarity, extinction risk, and conservation priority. Conservation Biology, 17, 1559-1570.

Harvey, P., Nellist, D. \& Telfer, M. (2002) Provisional atlas of British spiders (Arachnida, Araneae). Vol. 1 and 2. Biological Record Centre, Huntington.

He, F. \& Condit, R. (2007) The distribution of species: occupancy, scale, and rarity. Scaling biodiversity (ed. by D. Storch, P.A. Marquet and J.H. Brown), pp. 32-50. Cambridge University Press, Cambridge.

Isaac, J.L., Vanderwal, J., Johnson, C.N. \& Williams, S.E. (2009) Resistance and resilience: quantifying relative extinction risk in a diverse assemblage of Australian tropical rainforest vertebrates. Diversity and Distributions, 15, 280-288.

IUCN (2003) Guidelines for application of IUCN red list criteria at regional levels: version 3.0. IUCN Species Survival Commission, Gland and Cambridge.

Jetz, W., McPherson, J.M. \& Guralnick, R.P. (2012) Integrating biodiversity distribution knowledge: toward a global map of life. Trends in Ecology \& Evolution, 27, 151-159.

Kattan, G.H. (1992) Rarity and vulnerability: the birds of the Cordillera Central of Colombia. Conservation Biology, 6, 64-70.

Kier, G., Kreft, H., Lee, T.M., Jetz, W., Ibisch, P.L., Nowicki, C., Mutke, J. \& Barthlott, W. (2009) A global assessment of endemism and species richness across island and mainland regions. Proceedings of the National Academy of Sciences USA, 106, 9322-9327.

Leroy, B., Pétillon, J., Gallon, R., Canard, A. \& Ysnel, F. (2012) Improving occurrence-based rarity metrics in conservation studies by including multiple rarity cut-off points. Insect Conservation and Diversity, 5, 159-168.

McCreadie, J. \& Adler, P.H. (2008) Spatial distribution of rare species in lotic habitats. Insect Conservation and Diversity, 1, 127-134.

McGill, B.J. (2010) Matters of scale. Science, 328, 575-576.

Pärtel, M., Kalamees, R., Reier, Ü., Tuvi, E.L., Roosaluste, E., Vellak, A. \& Zobel, M. (2005) Grouping and prioritization of vascular plant species for conservation: combining natural rarity and management need. Biological Conservation, 123, 271-278.

Pearman, D. (1996) Presidential address, 1996. Towards a new definition of rare and scarce plants. Watsonia, 21, 231-251.

Pearman, P.B., Penskar, M.R., Schools, E.H. \& Enander, H.D. (2006) Identifying potential indicators of conservation value using natural heritage occurrence data. Ecological Applications, 16, 186-201.

Pétillon, J., Courtial, C., Canard, A. \& Ysnel, F. (2007a) First assessment of spider rarity in Western France. Revista ibérica de aracnología, 15, 105-113.

Pétillon, J., Georges, A., Canard, A. \& Ysnel, F. (2007b) Impact of cutting and sheep grazing on ground-active spiders and carabids in intertidal salt marshes (Western France). Animal Biodiversity and Conservation, 30, 201-209. Pétillon, J., Georges, A., Canard, A., Lefeuvre, J.C., Bakker, J.P. \& Ysnel, F. (2008) Influence of abiotic factors on spi- der and ground beetle communities in different salt-marsh systems. Basic and Applied Ecology, 9, 743-751.

R Core Team (2012) R: A language and environment for statistical computing. R Foundation for Statistical Computing, Vienna.

Rabinowitz, D. (1981) Seven forms of rarity. The biological aspects of rare plant conservation, vol. 1 (ed. by H. Synge), pp. 205-217. Wiley, New York.

Rands, M.R.W., Adams, W.M., Bennun, L., Butchart, S.H.M., Clements, A., Coomes, D., Entwistle, A., Hodge, I., Kapos, V., Scharlemann, J.P.W., Sutherland, W.J. \& Vira, B. (2010) Biodiversity conservation: challenges beyond 2010. Science, 329, 1298-1303.

Samu, F., Csontos, P. \& Szinetár, C. (2008) From multi-criteria approach to simple protocol: assessing habitat patches for conservation value using species rarity. Biological Conservation, 141, 1310-1320.

Schneider, D.C. (2001) The rise of the concept of scale in ecology. BioScience, 51, 545-553.

Simaika, J.P. \& Samways, M.J. (2009) An easy-to-use index of ecological integrity for prioritizing freshwater sites and for assessing habitat quality. Biodiversity and Conservation, 18, 1171-1185.

Soberón, J., Jiménez, R., Golubov, J. \& Koleff, P. (2007) Assessing completeness of biodiversity databases at different spatial scales. Ecography, 30, 152-160.

Warman, L.D., Sinclair, A., Scudder, G., Klinkenberg, B. \& Pressey, R.L. (2004) Sensitivity of systematic reserve selection to decisions about scale, biological data, and targets: case study from southern British Columbia. Conservation Biology, 18, 655-666.

Ysnel, F., Pétillon, J., Gerard, E. \& Canard, A. (2008) Assessing the conservation value of the spider fauna across the West Palearctic area. Journal of Arachnology, 36, 457-463.

Zamin, T., Baillie, J., Miller, R., Rodríguez, J., Ardid, A. \& Collen, B. (2010) National red listing beyond the 2010 target. Conservation Biology, 24, 1012-1020.

\section{SUPPORTING INFORMATION}

Additional Supporting Information may be found in the online version of this article:

Appendix S1 Modification of the original weighting function by Leroy et al. (2012)

Appendix S2 Demonstration of the equitability property of the flexible weighting function.

Appendix S3 Spatial referencing of records at the western Palearctic scale.

Appendix S4 Occurrences and rarity weights of spider species.

Appendix S5 Indices of relative rarity and rankings of spider assemblages. 


\section{BIOSKETCHES}

Boris Leroy is a $\mathrm{PhD}$ student at the Muséum National d'Histoire Naturelle of Paris and has special interests in conservation biogeography and climate change. His thesis focuses on the development and application of robust and general tools (rarity indices and species distribution models) for the conservation of lesser-known taxa such as invertebrates.

Alain Canard is professor at the University of Rennes 1. His research is dedicated to the biogeography, systematic and conservation of spiders and terrestrial arthropods. $\mathrm{He}$ is currently compiling a database of all available resources (bibliography, databases and specialists) for terrestrial arthropod taxa of Western Europe.

Frédéric Ysnel is assistant professor at the University of Rennes 1. His research is dedicated to the ecology and bioassessment of lesser-known taxa with a strong focus on applied conservation. His current projects span terrestrial and marine invertebrate taxa.

Author contributions: BL and FY designed the study. BL designed the methodology and performed analyses. AC and FY compiled the databases with help from BL. BL wrote the first draft of the manuscript, and all the authors contributed substantially to writing.

Editor: Alan Andersen 